\title{
Study on the Causes of Disappearance of China's Regional Dance and its Live Transmission: A Case Study of Bamboo Dance of Hainan Li Nationality
}

\author{
Li Wang $^{1}$, Xiuqing Fang ${ }^{2}$ \\ ${ }^{I}$ Associate Professor, Department of Dance, School of Music and Dance, Hainan University, China, \\ wangli_well@hainanu.edu.cn \\ ${ }^{2}$ Adjunct Professor, Media \& Arts Management, Sogang University, Korea, artist@sogang.ac.kr
}

Corresponding author: Xiuqing Fang

\begin{abstract}
As a multi-ethnic country, China boasts many kinds of regional dances. However, the development of such dances has been greatly hindered due to the absence of the written records and lack of effective ways to be inherited. Up to now, more than 800 kinds of dances have been extinct, and some are on the verge of disappearance. The fact has shown that it is high time to protect and inherit China's regional dance. In view of the development status of the bamboo dance in Hainan, this study uses literature research and field research methods to conduct in-depth study on the historical origin, artistic characteristics, cultural connotation and social value of the bamboo dance, and analyzes the reasons for its loss. Through interviews with experts and scholars, government administrators, non-hereditary inheritors and representative local people, the present situation and difficulties of The Li nationality bamboo dance are fully reproduced. On the basis of summing up experience and lessons, a series of mechanisms for effectively protecting and inheriting Hainan Li nationality bamboo dance is tentatively constructed. The results show that: First, the origin of bamboo dance is numerous, but the religious origin is more reliable; Second, the artistic characteristics of bamboo dance are rich and diverse. The integration of movement elements of external dance makes the original ecological dance of our nation more and more mutated and weakened; Thirdly, with the development of The Times, the nature, function, expression form and cultural connotation of Li Nationality bamboo Dance have undergone great changes; Fourth, the rites of mourning of the Li people in Hainan have been simplified and sinicized, which has changed the function and social value of the Li people's bamboo dance. Fifth, the lack of successors, the rapid development of economy and culture, insufficient government support, people's weak awareness of the protection of national and regional culture, high-tech and accelerated urbanization have all become factors affecting the protection and inheritance of bamboo dance. The significance of this study is conducive to an in-depth understanding of the protection and inheritance of Chinese regional intangible heritage dances, and can provide reference materials for the subsequent study of the bamboo dance of Hainan intangible heritage dances.
\end{abstract}

Keywords: China's Regional Dance, Bamboo Dance, Imminent Disappearance, Digital Technology, Live Transmission

\section{Introduction}

In the process of social and historical changes in China, under the influence of political and economic systems, a large number of traditional dance cultures have disappeared. Although the traditional regional

Received: May 19, 2021; $1^{\text {st }}$ Review Result: July 04, 2021; $2^{\text {nd }}$ Review Result: August 22, 2021

Accepted: September 30, 2021 
folk dance is handed down, with the loss of time, the traditional regional folk dance has changed more or less, and some are facing extinction.

On May 6, 2018, the first China Dance Forum was held in Shanghai Literature \& Art Hall. Qu Shengrui, former deputy director of Department of Intangible Cultural Heritage, pointed out that at present, there are 113 dances in the national intangible cultural heritage list, accounting for $9.1 \%$ of the total. It is surveyed that by the $1990 \mathrm{~s}, 853$ of 2,100 traditional dances had disappeared, among which, two thirds of folk dances in central China no longer exist.

Located in the southernmost part of China, Hainan is blessed with unique regional dance culture. On May 20, 2006, approved by the State Council of the People's Republic of China, bamboo dance of Li nationality was included in the second batch of national intangible cultural heritage list, with the heritage number III-32. According to the statistics of http://www.ihchina.cn/, a website of The Intangible Cultural Heritage in China, a total of 324 dances are recorded by National Intangible Cultural Heritage, and 298 people are rated as national-level dance inheritors, among whom, people over 80 years old account for $24 \%$, between $70-79$ for 35\%, 60-69 for 19\%, 50-59 for 19\%, and under 40 for only 3\%[1].

Judging from the statistics above, it indicates that China's regional dance is in dire need of people's protection and inheritance. Today, with the rapid development of global integration western culture and entertainment have greatly influenced the life of Chinese people, which leads to marginalization of China's regional dance[2]. Thus, the purpose of this research is to further protect and inherit China's regional dance, and provide an effective way to strengthen national unity and maintain a harmonious relationship among peoples in the world.

\section{Literature Review}

Among the few references of regional intangible cultural heritage dance of Li nationality, scholars have defined the origin and artistic characteristics of intangible cultural heritage dance of Li Nationality from different angles and fields. Articles on the intangible cultural heritage protection of Chinese traditional musical instruments, and articles on the inheritance and protection of local operas. In August 2021, J. W. Xu and X. Q. Fang published the academic paper "Protection and Inheritance of Local Dramas in China: A Case Study of Liuqin Troupe in Pizhou City", which aims to contribute to the protection and inheritance of Chinese local dramas by analyzing and studying the development status of Liuqin opera, China's intangible cultural heritage[3]. In October 2020, X. Q. Fang published an academic paper "A Historical Study of the Zhu, a Traditional Chinese String Instrument", which is an article on the protection of traditional musical instruments[4]. In April 2020, K. Wang published an academic paper "on the inheritance and development of Li Folk Dance in Hainan" in Chinese writers and artists[5]. In September 2019, R. Q. Sun published an academic paper "Cultural Characteristics and Style Characteristics of Hainan Li Dance" in mass literature and art[6]. Y. Jiang academic paper "Analysis on the cultural and artistic value and inheritance of Li nationality dance" published in the Journal of Jilin radio and Television University in December 2017 briefly analyzes the origin, form and characteristics of Li nationality folk dance from the perspective of the inheritance and development of Li nationality dance in Hainan[7]. In April 2018, G. Ya published his academic paper "Analysis on the cultural and artistic value and inheritance of Li dance" in the Journal of Hainan Tropical Oceanography University. Taking ancestral song and bamboo dance as examples, from the aspects of music morphology, dance aesthetics, dance physique and new pragmatism aesthetics From the perspective of poetics, this paper expounds the formation and evolution of different periods and the integration of intercultural perspectives, so as to reflect the spirit of Li culture[8]. In May 2019, J. H. An academic Article a Brief Talk on the Form and Social function of Li's Bamboo Dance was published in Drama House. It mainly discussed the form of performance and social function of Li's bamboo dance in ancient and modern times. In summary, at present, the literature on the research of Hainan bamboo dance mostly focuses on 
the research of artistic characteristics and style characteristics, and also from the perspective of aesthetics. However, there are few research materials on the lost factors and living inheritance of bamboo dance. Therefore, this research is both necessary and practical.

In 2013, general secretary Xi Jinping, presiding over twelfth collective study sessions at the Politburo of the Communist Party of China, proposed bringing those hidden relics and obscure ancient books to public, which therefore makes live transmission of intangible cultural heritage possible.

In 2018, Duan Baolin, a professor of folklore at Peking University, said in his book The Essence of Intangible Cultural Heritage that the intangible cultural heritage can be protected in two ways: one is static, the other is dynamic[9]. In terms of his opinion, some scholars think that as long as it is dynamic, it is a kind of live transmission, while the author believes that live transmission means it is once again exposed to people's daily life after art refining, and it is closely related to people and their lifes. On the basis of preserving the essence of the regional dance culture and continuing its ideological and artistic characteristics, creative elements should be applied in the dance; meanwhile, the lifestyle of Li people needs to be reflected in it. Thus, such a dance performed by Li people is a useful way of live transmission.

\section{Research Methods}

\subsection{Research Design}

Bamboo dance of Li nationality is chosen as the subject of the case study in the paper. In order to find out the causes of disappearance of bamboo dance and explore an effective way of inheritance, this paper summarizes the historical origin, artistic characteristics, cultural connotation and social value of Li's bamboo dance by means of literature research. To be specific, the inheritors of bamboo dance in $\mathrm{Li}$ villages were interviewed and field surveys were conducted to collect data and analyze the reasons for its disappearance. As to on-site investigation, culture centers in cities and counties were visited to experience the whole process of bamboo dance and collect relevant first-hand information, which lays a solid foundation to better protect and inherit the bamboo dance.

\subsection{Sample Selection}

The bamboo dance of Li Nationality in Hainan was successfully listed in the first batch of national intangible cultural heritage in 2006. The reason why the dance can successfully apply for the World Heritage List is that, on one hand, there were historical records on the funeral rites of Li nationality in Yazhou Chronicle of Guangxu in the Qing Dynasty, which provided solid and powerful evidence for the history of the dance of Li nationality in Sanya. On the other hand, there is a video from the 1980s. This precious video was shot by the deputy director of the Hainan Museum of Nationalities, who happened to be from Langdian Village, the hometown of the dance. He recorded it with his own equipment when he saw others dancing at a funeral in the village. Although the quality of the picture recorded at night is not particularly clear, it has recorded the original style and style of the dance, which has become the earliest video data of the dance. It is precise because of the above two historical records, so that the bamboo dance in Sanya in the "application for World Heritage" occupied the vast advantage. Huang Jiajin, a villager of Langdian Village, who is the inheritor of the bamboo dance of the Li nationality, always organizes the villagers and takes the lead in performing the bamboo dance according to the customs whenever there is a funeral in the village, making important contributions to the complete preservation and long-term inheritance of the bamboo dance.

In the language of Li nationality, bamboo dance is called "Zhuan Sha" or "Tai Sha". It was originally performed only in funerals. After the national liberation, combined with some creative designs, it later 
became a popular dance for entertainment and fitness among Li people. As of 2021, there are a total of 11 dance categories in the current list of intangible cultural heritage protection in Hainan, including 9 intangible cultural heritage dances at the provincial and municipal levels in Hainan, and 2 national intangible cultural heritage projects[10]. The Li nationality's bamboo dance is one of them. Therefore, this article chooses the Hainan Li nationality's bamboo dance as an example for analysis and research.

\subsection{The Data Collection}

The data collection period of this study is from March 2020 to April 2021. The survey investigates the specific inheritance ways and methods of the Li ethnic group's bamboo dance in Hainan, the attitude, interest and mastery of the Li ethnic group's local teenagers and middle-aged and elderly people on the bamboo dance, and analyzes the specific causes and manifestations of the inheritance dilemma of the Li ethnic group's bamboo dance. Aiming at the five dimensions of this study, namely the origin of Hainan bamboo dance, the artistic characteristics of bamboo dance, the cultural connotation of bamboo dance, the social value of bamboo dance and the lost factors of bamboo dance, set up twelve problems, in Haikou, LeDong Li Autonomous County, SanYa, Bao Ting Li and Miao Autonomous County, Wu zhi shan, Chang jiang Li Autonomous County conducted 6 interviews with 10 people.The interviewees are divided into four categories. The first category is Li culture expert Professor Zhou and President Wang; The second category is Director Fu and curator Zhang, managers of government departments; The third category is Mr. Huang Lao and Ms. Liu, the inheritors of intangible cultural heritage. The fourth category is to select representatives of the local people of Li nationality at different ages, including the elderly, middle-aged, young and young. Professor Zhou of Hainan University is an expert who has been engaged in the study of $\mathrm{Li}$ culture for many years. He analyzes the origin of bamboo dance and the artistic characteristics of bamboo dance; Mr. Huang Lao of Sanya is a national intangible cultural heritage inheritor of bamboo dance. He loves bamboo dance and is determined to inherit and carry forward bamboo dance. He interviewed how to protect and inherit bamboo dance and the origin of bamboo dance; Ms. Liu of Wuzhishan is the inheritor of the intangible cultural heritage of Li brocade. She has devoted herself to studying the textile technology of traditional Li brocade for many years, and put forward her own ideas on the characteristics of Da Chai dance clothes, how to improve Li costumes and why to improve them; Director Fu of Baoting and four mass representatives interviewed answered questions about Li's cognition of bamboo dance and whether they were willing to learn bamboo dance; Curator Zhang of Ledong former cultural center talked about his own views on the functions and lost factors of bamboo dance; President Wang of Changjiang talked about the role of bamboo dance in the inheritance of national culture and the social value of bamboo dance. Table 1 below is the interview record of bamboo dance.

[Table 1] The Interview Record of Bamboo Dance

\begin{tabular}{|c|c|c|c|c|}
\hline $\begin{array}{c}\text { Serial } \\
\text { number }\end{array}$ & Time & Place & Interviewee & Interview questions \\
\hline 1 & 2020.3 & $\begin{array}{l}\text { Hainan } \\
\text { University }\end{array}$ & Professor Zhou & $\begin{array}{l}\text { Question 1: the origin of bamboo dance } \\
\text { Question 2: the artistic characteristics of bamboo dance }\end{array}$ \\
\hline 2 & 2020.6 & Sanya & Mr. Huang & $\begin{array}{l}\text { Question 3: the historical category of bamboo dance } \\
\text { Question 4: the protection and inheritance of bamboo dance }\end{array}$ \\
\hline 3 & 2020.8 & Wuzhishan & Ms. Liu & $\begin{array}{l}\text { Question 5: the characteristics of bamboo dance costumes } \\
\text { Question 6: the innovation of Li's clothing }\end{array}$ \\
\hline 4 & 2020.11 & $\begin{array}{c}\text { Baoting Li and } \\
\text { Miao } \\
\text { Autonomous } \\
\text { County }\end{array}$ & $\begin{array}{c}\text { Director Fu Four } \\
\text { mass } \\
\text { representatives }\end{array}$ & $\begin{array}{l}\text { Question 7: about the cognition of bamboo dance } \\
\text { Question 8: how do you like bamboo dancing }\end{array}$ \\
\hline
\end{tabular}




\begin{tabular}{|c|c|c|c|c|}
\hline 5 & 2021.2 & $\begin{array}{l}\text { Ledong Li } \\
\text { Autonomous } \\
\text { County }\end{array}$ & Curator Zhang & $\begin{array}{l}\text { Question 9: the function of bamboo dance } \\
\text { Question 10: the reasons for the loss of bamboo dance }\end{array}$ \\
\hline 6 & 2021.4 & $\begin{array}{l}\text { Changjiang Li } \\
\text { Autonomous } \\
\text { County } \\
\text { Cultural Park }\end{array}$ & President Wang & $\begin{array}{c}\text { Question 11: the problem of bamboo dance in the inheritance } \\
\text { of national culture } \\
\text { Question 12: the social value of bamboo dance }\end{array}$ \\
\hline
\end{tabular}

\section{Live Transmission of Hainan Bamboo Dance}

\subsection{Origin and Development of Li's Bamboo Dance}

Li nationality in Hainan has not written its own words, and what Li people speak belongs to one of Sino-Tibetan languages. Generally speaking, Li dialect consists of Ha, Qi, Sai, Run, and Meifu. Because $\mathrm{Li}$ people speaking different dialects live in different regions, the style, form of performance and also cultural connotation of their own dances vary[11]. Unlike dances of some other ethnic groups, its form of origin is less diverse, but the theme of performance is very rich, such as legend, labor, or family tree. Such classic performances remain popular from one generation to another.

There are often three versions about how Li's bamboo dance comes into being. The first one is that it originated from one legend. According to A Collection of Chinese Folk Dances, a pair of young lovers of Li sang in a mountain, and the sweet songs stimulated many young men and women to sing and dance together day and night. It was pity that after eating poisonous fruit carelessly, they all died. From then on, when rainy season came, singing and sound of beating wood could be heard from the mountain. The second is related to the labor of Li people. In the primitive age, Li people lived in houses made of bamboo. Bamboo poles could roll down from roof to the ground when they built their homes. In order to dodge the rolling bamboo poles, Li people had to jump here and there.

As to the third one, sacrificial funeral makes the birth of the dance possible. Dry Race is a special funeral of Li nationality, after the death of a person, the coffin had to be kept at home for 12 days, 24 days, or even one month. During this period, relatives and friends of the deceased would visit his or her home and performed bamboo dance. It is written in Yazhou Record Li Story that in the funeral, if the deceased grandfather was not put in a coffin, his children and grandchildren would not use coffins too when they die. An ox must be killed as a sacrificial offering and people were required to the dance of bamboo. The author believes that the theory of sacrifice is more reasonable, because the Li Nationality in Hainan believes in "everything has spirit", resulting in nature worship, totem worship, ancestor worship and witchcraft activities, which occupies an important position in the spiritual life of the $\mathrm{Li}$ people. Therefore, the author believes that the bamboo dance was originally based on the Li Folk funeral custom, which is more credible.

The protection of China's regional intangible cultural heritage dance cannot just stay in the museum and the inheritor itself. The real protection is inheritance and development. To develop, we must inherit first. Without inheritance, there is no development[12]. In the survey, it is found that everywhere I go, the author can watch the local bamboo dance, including the bamboo dance spontaneously organized by the local people, as well as the organized, large-scale and planned arrangement and formal performance of cultural media companies and scenic spots. Whether it is the spontaneous form of the people or the formal performance, there will be many audiences around, most of whom are tourists. During the dance, the dancer will invite the audience to participate in the dance. Therefore, it is not difficult to see that with the development of the times, the social attributes and artistic characteristics of bamboo dance are also changing. On the basis of retaining the elements of traditional bamboo dance, many regions integrate modern expression methods, reprocess and move to the stage on the basis of the original bamboo dance form and folk customs. bamboo dance not only solves the employment problem of local 
people, but also drives the development of other related industries. Taking the traditional dance of Hainan Li nationality as a cultural and economic resource is beneficial to the economic development and social stability of Hainan Li nationality area.

After the founding of the People's Republic of China, in order to protect the soon-to-be-lost regional dance, Hainan government began to collect, process and sort out all the materials and costumes related to Li's bamboo dance, in the hope of staging for folks. Bamboo dance has experienced many various changes ranging from form of performance, movements, and props to performance venue. Ultimately, the charm of Li's bamboo dance has shone throughout the world.

\subsection{Artistic Features of Li's Bamboo Dance}

Affected by the natural environment, Li's bamboo dance is characterized by small steps. Furthermore, the range of the crotch and the movement of the upper limbs often form one-sided and S-shaped postures[13]. Before performing bamboo dance, two thick bamboo poles are placed parallel to each other on the ground. The distance between the bamboo poles is three meters. There are six to ten people to beat the poles: two in a group are at two ends of one thin pole; two (one next to another) get on knees with backsides on the ground and the distance between them is a little wider than an arm; two (opposite to each other) hold a pair of bamboo poles. Apart from that, one pole is held by one hand. In the process of beating poles, one hand moves forward while the other moves backward. Make sure poles are beat instead of hands being beat by poles. When the dance starts, two ends of the poles are in the hands of holders, who beat poles up and down, left and right, open and close, or crossed. Then, the dancers in the middle make various movements among the poles. The stage can be arranged in sequence by many people, or the positions can be changed into groups of two people. As the dancers agilely jump out of poles, pole-holders shout "Hey, yo hey" in chorus. as shown in [Fig. 1].

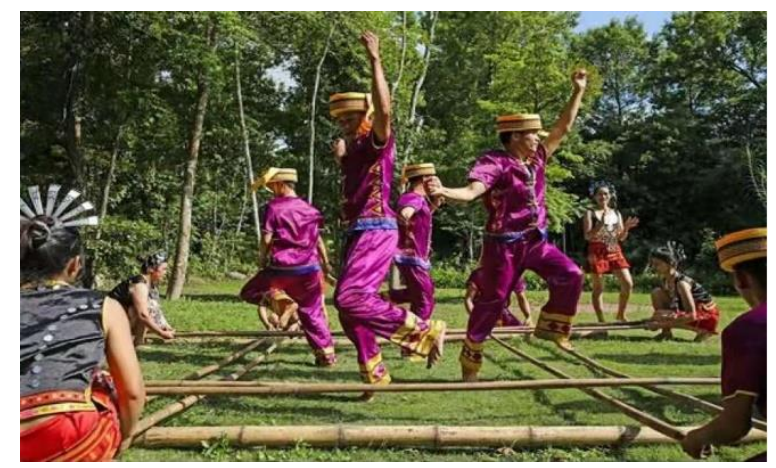

[Fig. 1] Bamboo Dancing

In view of the origin of bamboo dance, Professor Zhou said in the interview that there are bamboo dances in the Philippines. The bamboo dances in the Philippines are similar to those in Hainan. They are both regional folk dances and well-known and loved folk dances. Although their origins are different, they are in the artistic style of the dance Artistic features and artistic forms of expression have something in common. In view of the artistic characteristics of bamboo dance in question 2, Professor Zhou said: "There are only nine basic dance steps in the most primitive bamboo dance, namely, the flat bamboo dance, the jumping dance, the knitting dance, the little frog dance, the big frog dance, the deer dance, the rice screen dance, the monkey dance and the crow dance." The order of the above nine dances cannot be reversed, and they can only start on the third day of the mortuary and stop until the day before the funeral. Modern bamboo dance performances have a variety of patterns, such as walking through the human wall, lovers on the road, dragon's Gate dance, etc. in the dance arrangement, dance elements 
such as drama hair throwing, hip twisting of aerobics, wrestling dance in Inner Mongolia and Spanish bullfighting dance are integrated to enhance the artistic appeal of bamboo dance.

During his visit to Langdian village in Sanya, Mr. Huang Lao, as a national intangible cultural heritage inheritor of bamboo dance, had his own views on the third question, the nature of bamboo dance and the fourth question, how to inherit and protect it. He said that the Li people believed that the bamboo dance at the funeral ceremony was to surpass the dead. In the past, the bamboo dance was not danced casually, which could only be seen at the funeral. Although today's young people are not enthusiastic about bamboo dance, they hope to continue to inherit bamboo dance by setting up training courses and establishing a transmission base. Under the influence of religious belief, dancers jump to the rhythm of arm-opening, hand-waving, turning and some other movements full of vigor, displaying the features of worship and labor. The basic steps are composed of mimicking the movements of frog, deer, monkey, crow, knife-sharpening, sieving rice and so on. as shown in [Fig. 2] and [Fig. 3].

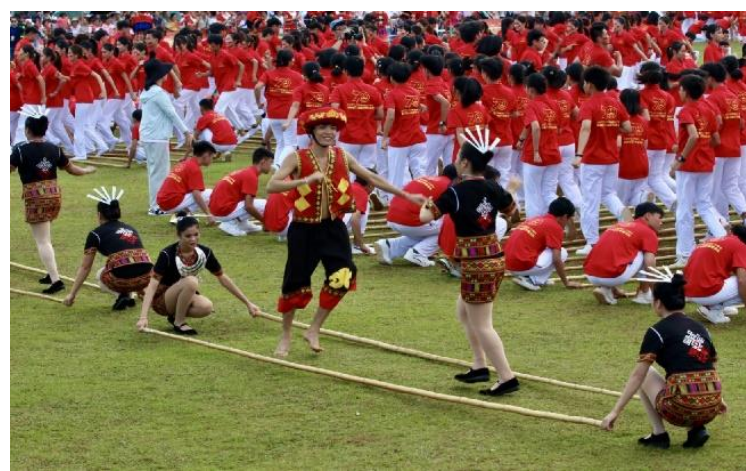

[Fig. 2] Ten Thousand People Dance Bamboo Dancing

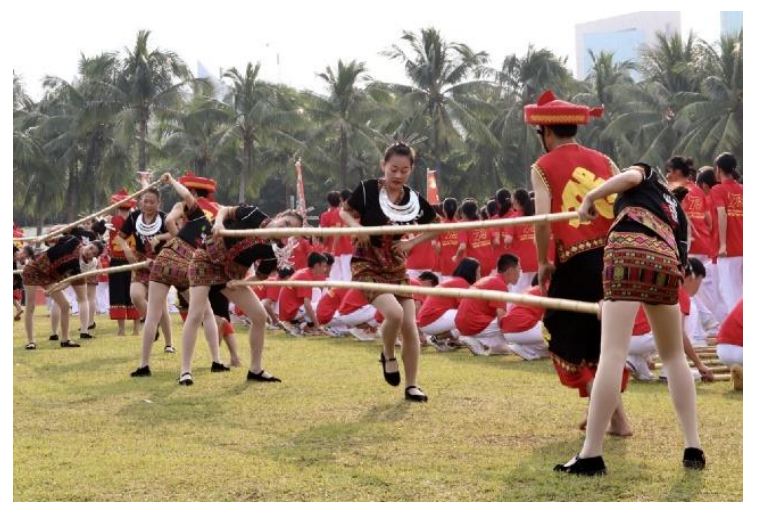

[Fig. 3] Jump to the Dragon Gate Bamboo Dance

In view of the clothing characteristics of question five bamboo dance and the clothing innovation of question six Li nationality, in Chongshan Town, Wuzhishan, the author met Ms Liu, the inheritor of the intangible heritage of Li brocade. According to her, Wuzhishan is a Qi dialect area. The clothes worn by adult women in this area are round neck long sleeves, button free jacket and knee length skirt, and the traditional adult men's jacket is open chest, button free and buckle free, there is a rope to tie the clothes. There are many tassels on the back edge of the clothes. The lower garment is "egg wrapped cloth" or "split skirt".

The traditional costumes that Li people wear in bamboo dance are quite gorgeous. Male performers' costumes are mainly made up of red and yellow, they are dressed in red waistcoats edged with yellow and black loose pants blended with red; while female performers are usually in traditional Li costumes, 
they wear blouses with black round collars and skirts, and have a classic up-do with headdresses. The moon-like silver ornaments on their chests make pleasing sounds when jumping.

With the rise of fashion industry, the traditional clothing of Li nationality has also changed. In order to enhance the aesthetics of bamboo dance and the comfort of clothing, and facilitate the completion of dancers' movements during dancing, the designer has changed the clothing style, color and fabric. The fabric of clothing has been changed from the original manual woven fabric to the modern printed blended fabric, which is light and breathable, the colors are also much brighter than traditional costumes. Therefore, the innovative Li costumes have played a decorative and beautifying effect in the display of bamboo dance. After analyzing the interview records of field research, the following conclusions are drawn: today's bamboo dance is no longer the original Hainan regional dance, and the dance form of bamboo dance has changed, From irregular to regular, the action line changes composition from simple to multi-directional; Props from the original heavy red Suzuki into a relaxed bamboo pole; The dancers changed from men dancing bamboo and women fetching bamboo to men and women dancing together; The performance venue developed from narrow ground to square; Clothing changed from traditional $\mathrm{Li}$ clothing to innovative clothing; The category of dance has changed from sacrificial to entertaining. bamboo gathering dance has gradually stepped out of Li villages and entered the stage of the world. In addition, musicians adapted the Li Folk Dance Music youth dance music into today's bamboo song and dance music, from the initial percussion accompaniment to modern music accompaniment. The following table 2 is a comparison of the artistic characteristics of bamboo gathering dance of $\mathrm{Li}$ Nationality in Hainan.

[Table 2] Comparison of the Artistic Characteristics of Bamboo Gathering Dance

\begin{tabular}{|c|c|c|c|c|c|c|c|c|}
\hline $\begin{array}{c}\text { Comparison } \\
\text { of artistic }\end{array}$ & $\begin{array}{c}\text { Dance } \\
\text { form }\end{array}$ & $\begin{array}{c}\text { Action } \\
\text { route }\end{array}$ & $\begin{array}{c}\text { The } \\
\text { accompanime }\end{array}$ & The dancer & The props & place & clothing & $\begin{array}{c}\text { The dance } \\
\text { category }\end{array}$ \\
\hline $\begin{array}{c}\text { Before the } \\
\text { innovation }\end{array}$ & irregular & simple & $\begin{array}{c}\text { Bamboo and } \\
\text { wood percussion } \\
\text { rhythm }\end{array}$ & $\begin{array}{c}\text { Men jump } \\
\text { bamboo and } \\
\text { women pick } \\
\text { bamboo }\end{array}$ & Red Suzuki & field & $\begin{array}{c}\text { Traditional } \\
\text { clothing }\end{array}$ & Sacrificial \\
\hline $\begin{array}{c}\text { After the } \\
\text { innovation }\end{array}$ & The rules & diversified & $\begin{array}{c}\text { Modern music } \\
\text { accompaniment }\end{array}$ & Mixed jump & bamboo & square & $\begin{array}{c}\text { Improve } \\
\text { clothing }\end{array}$ & Entertaining \\
\hline
\end{tabular}

\subsection{Cultural Connotation of Li’s Bamboo Dance}

During the field investigation and interview, in view of the cognition of bamboo dance in question 7 and the preference for bamboo dance in question 8, Director $\mathrm{Fu}$, the person in charge of MaoGai Township, District 1, Baoting County, told the author that with the development of commodity economy and the change of cultural lifestyle, the young people of Li nationality are more willing to accept new things and cultural education. Now many local young people can't dance, in order to understand the local Li people's cognition of bamboo dance, the author randomly selected a 10-year-old primary school student, a 25-year-old young man, a 48 year old middle-aged woman and an 83 year old man, and put forward "which ethnic minority characteristic dance is bamboo dance? How about bamboo dance, $50 \%$ of them answered that they don't know about it, and whether they are willing to learn bamboo dance" $50 \%$ of them said they were willing to learn bamboo dance, but they had to give up because they were too old and were not flexible. Although bamboo dance has changed to modern functions such as entertainment and fitness, it is still at a disadvantage in social competition. Therefore, bamboo dance, like other Chinese minority traditional cultures, is also facing decline, variation and even extinction in the process of modern inheritance. Through the sorting of interview records, the author finds that people 
of different ages have different value orientations. In terms of bamboo dance, young people pay more attention to self-awareness and have little awareness of national cultural protection and inheritance. Adults pay more attention to understanding the connotation of national culture and the protection and inheritance of their own national culture. The following table 3 shows the cognition of bamboo dance function.

[Table 3] Cognition of Bamboo Dance Function

\begin{tabular}{|c|c|c|}
\hline Cognition of bamboo dance & Do you know bamboo dance & $\begin{array}{c}\text { Would you like to learn bamboo } \\
\text { dance }\end{array}$ \\
\hline 10 years old & Do not understand & unwilling \\
\hline 25 years old & Do not understand & unwilling \\
\hline 48 years old & understand & be willing \\
\hline 83 years old & understand & be willing \\
\hline
\end{tabular}

Li's bamboo dance is the living fossil of Li's corpse-protecting dance in the ancient times. The dance still retains its deep cultural connotation since its birth and inheritance. For example, the stomping movement is characterized by the situation that the dancer first tentatively extends his left foot toward the closed bamboo poles, then retracts two times and presses his opposite right foot into the opening of the bamboo poles in front of him or her, which is to tell the deceased to explore ways to meet their ancestors, not to get lost or go astray. The feature of the frog step is to imitate the size of the frog jump with four feet on the ground, slowly and quickly over the bamboo square, meaning that if the deceased encountered a small obstacle, just cross over it with light steps with no fear. The crow-flying step is demonstrated like this: when pole holders slowly lift the poles high, a dancer mimics a crow flapping its wings, then jumps over the pole through a gap and stands on one foot with open arms like a flying crow, which seems to say to the deceased: We have entrusted the crow to send your soul to you, and the ancestors have also agreed, just rest in peace[14].

There was no music accompaniment in early bamboo dance. At that time, males danced among the bamboo poles, while females beat poles, which is in accordance with the social practice that women in Hainan often work outside. At present time, it has changed, and dancing and beating are performed by male and female. Li people can find partners, set up Magpie Bridge and establish an intimate relationship in the dance, so it has become a unique way for young people of Li to meet, know, and love each other.

Curator Zhang, of the former Ledong County Cultural Center, told the author that the traditional bamboo dance mainly has two functions, one is the function in the sense of religion, and the other is a means of communication between young men and women. With the development of society, the function of Li bamboo dance as a way of communication between men and women of Li youth is also weakening. Modern high technology and multimedia technology make the places for Li youth to make friends from "longboudoir" to society. Wechat, circle of friends and short videos can make strangers become "friends" in just a few seconds. Complex bamboo dance steps and dangerous bamboo dance styles are no longer accepted by young people.

\subsection{Social values of Li's Bamboo Dance}

At the Changjiang Li and Miao culture forum in Hainan in 2021, the author met with President Wang, vice president of Hainan ethnic society. Regarding the role of problem 11 bamboo dance in the inheritance of national culture and the social value of problem 12 bamboo dance, President Wang said that Li bamboo dance plays an important role and significance in the inheritance of national culture and 
the construction of Hainan free trade port. Since ancient times, Hainan Island has been regarded as a "place of malaria and wilderness", with low economic level, lack of cultural heritage and low people's living standard. After the establishment of the province, with the encouragement of national preferential policies, Hainan's economy has developed rapidly. The local Li people gradually pay attention to the protection and inheritance of their national culture. Regional culture and foreign cultural and artistic exchange activities are increasing day by day, which provides a good development platform for the foreign communication and exchange of $\mathrm{Li}$ bamboo dance.

As Hainan is making itself an international tourist island, cultural construction becomes a vital task for Hainan. It is a must to give full play to the social values of local excellent regional culture To promote the development of regional economy and culture through protection and inheritance of local intangible cultural heritage which is a kind of optimal live transmission[15]. After China's success in poverty alleviation, the overall promotion of rural revitalization will become the main theme of development in the next few years. The live transmission of Hainan folk dance not only embodies the cultural features of Li people, but also helps inject the potential energy into local economy, thus playing an important role in the revitalization of Li villages.

In order to create a pattern of all-round opening to the outside world and inherit the cultural heritage of South Africa, the Hainan Provincial Government strives to create intangible heritage products that integrate tradition and fashion, inject intangible heritage culture into the tourism industry, and create a cultural, tourism and art business with local characteristics. The special economic zone in Hainan provides support for cultural development and provides effective support for the inheritance of dance art culture and the display of technological value. The construction of an international tourist island should not only pay attention to the development of tourism, but also the protection and excavation of national culture. Protecting and excavating national culture is the basic condition for the development of tourism. Unique culture is the core of modern tourism. "The more national, the more global." This sentence highlights the importance of national culture[16]. Protection is a kind of respect and affirmation of national culture, and development is a kind of promotion and active use of national culture, and it is also a higher meaning of protection.

\section{Reasons for Imminent Disappearance of Bamboo Dance}

Li's bamboo dance has a long history. Under the impact of the rapid development of modern society and tourism culture, there is insufficient support in the field of school education, imperfect public cultural service system, high-tech application, the dilemma of inheritors' fault, insufficient attention of the government, coupled with people's weak awareness of national cultural inheritance, interest transfer and function transformation, all these are the factors leading to the loss of bamboo dance of $\mathrm{Li}$ Nationality in Hainan.

So far, China's regional dance boasts a variety of artistic forms, but few young people have inherited such intangible cultural heritage. The rapid development of economy and culture has damaged the authenticity and integrity of the dance, making it unable to be well-protected[17]. To make things worse, the fast urbanization process has posed many serious problems, severely hindering the protection and inheritance of bamboo dance. This not only threatens the development of China's cultural industry but leads to the gradual extinction of the dance culture. From March 2020 to April 2021, the author has explored the root cause and difficulties in the development of Li's bamboo dance. For example, the research team came to Wuzhishan, Baisha, Changjiang and some other regions, where the dance is included in the heritage protection list, and conducted a number of field investigations. Moreover, local cultural centers were visited, and families of the inheritors were interviewed for collecting relevant data. Finally, conclusions are drawn from the analysis of the reasons why Li's bamboo dance is on the verge of extinction. 
The reasons are listed as follows:

First, Li's bamboo dance has many origins, but its religious origin is highly reliable;

Second, the artistic characteristics of bamboo dance are rich and diverse. The integration of action elements of foreign dance makes the native dance of our nation mutate and weaken day by day;

Thirdly, with the development of the times, great changes have taken place in the nature, function, manifestation and cultural connotation of Li bamboo dance;

Fourth, the funeral rites of Li Nationality in Hainan have been simplified and sinicized, which has changed the function and social value of Li nationality's bamboo dance;

Fifth, the lack of successors, the rapid development of economy and culture, the insufficient government support, the weak awareness of people's protection of their national regional culture, and the acceleration of high-tech and urbanization have become the factors affecting the protection and inheritance of Li bamboo dance.

In the protection and inheritance of Li's dance, the disconnection between theory and practice, and education and market demand are the internal causes of imminent disappearance of the dance, while the disconnection between inheritance and cultural connotation and the separation of digital technology and culture from industry are the external causes[18].

\section{Countermeasures on Live Transmission of China's Regional Dance}

Live transmission of China's regional dance is the result of policy implementation, and it comes into being inevitable when culture industry steps into a certain phase. Recently, the research on how to effectively protect and inherit Li's bamboo dance are scarce. So, based on an in-depth study of live transmission of Li's dance, the author puts forward the following countermeasures.

First of all, education is the foundation of the nation, and it should play a key role in the protection and inheritance of intangible cultural heritage. It is essential to establish a standardized and characteristic dance teaching method[19], help students understand the charm of the dance, and boost the awareness of protecting and inheriting it. Furthermore, the inheritors can be invited to conduct on-the-spot teaching and deliver academic lectures, and teaching and theory are combined with practice to create a pleasant live transmission of the dance culture for the young.

Then, it is advisable to establish a public cultural service system, improve the condition of dance training centers, foster more professional dancing teams, protect the rights and interests of the inheritors, and make the dance more accessible to the public. Local governments should financially support the inheritors and encourage them to further spread their culture with incentives. Only in this way can live transmission work.

Third, there is a need to strengthen the dance creation and expand the performance market. The real protection is inheritance and development. On the basis of inheriting the traditional bamboo dance, locals should be close to the times and life, and strive to create more vivid dance works.

Fourth, establish local protection and inheritance mechanisms. Local people's governments at all levels shall establish corresponding cultural heritage protection coordination institutions and form an organizational structure at the three working levels of administrative leadership, business management and specific implementation, so as to provide organizational guarantee for the effective and orderly protection of "intangible cultural heritage".

Furthermore, digital technology can be utilized to restore the nature of China's regional dance, so as to expand influence of the dance. In the early times, western countries have digitalized their artworks. With the continuous updates of digital technology, motion capture systems are widely used in the animation industry as a result of technological innovation, then developed into an effective model to protect intangible cultural heritage[20]. The display of digital relics has solved the limitation of space 
as well as continuity of dance moves to some degree with the help of AR, VR or other advanced technologies[21]. Therefore, to better spread culture, the application of this technology to live transmission of bamboo dance is a new measure proposed in this paper. Because dance move features continuity of space and time, traditional methods of description are no longer feasible[22]. After capturing dance moves by using sensors on dancers, the researchers then gave a systematic metadata description of these moves, which could be employed to capture and analyze the dancers' moves and to give feedback for improvement. By doing so, we can promote the study of bamboo dance while protecting it, to realize the actual purpose of live transmission. This technique is the most effective and optimal way to protect and inherit intangible cultural heritage in the future. In the era of application of high-tech and new media, it is a must to make the best of the world's advanced digital technology of scientific media to realize the simulation of time and space, and utilize the convergence of non-digital and intelligent media to make people fully understand the charm of Hainan's regional dance.

Besides, on the basis of the traditional media, presentation - repost - evaluation - discussion communication bamboon is established through a second round of transmission via new media[23]. Additionally, making short videos about bamboo dance helps to enhance its popularity through the notable online platform Douyin. At the same time, to deepen cooperation with other cities on intangible cultural heritage makes it more accessible to the public. These measures mentioned above enable live transmission of intangible cultural heritage to be successful.

As to the last one, intangible cultural heritage can be integrated with tourism to develop intangible cultural heritage projects and revitalize rural areas. On April 13, 2021, Bamboo Dance Competition was held at the Main Conference Hall of Baisha Li Autonomous County, and 11 teams from all over the county participated in it. While inheriting traditional culture, we might as well infuse the novel concepts into it to make a contribution to the construction of new rural culture and local financial development. as shown in [Fig. 4].

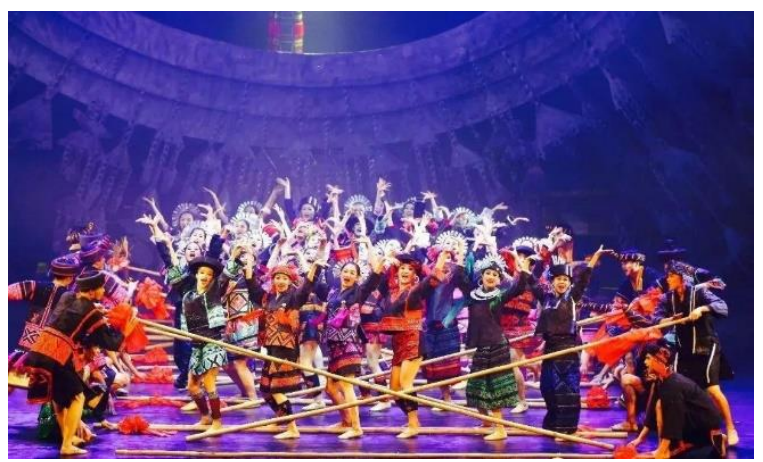

[Fig. 4] Song and Dance Drama of Bamboo Dancing

\section{Conclusions}

As a unique artistic performance, Hainan Li's bamboo dance is very popular in many regions among $\mathrm{Li}$ people and has been performed in mainland China and foreign countries. Bamboo dance is a group dance with high artistic research values, which plays an irreplaceable part in boosting a sense of unity among ethnic groups. To inherit bamboo dance is to carry forward Chinese traditional culture. Now, China plans to establish Hainan into the pivot of integrated areas in Asia. Based on this rare opportunity, digital media can be introduced into the protection of bamboo dance; besides, the combination of regional dance culture and Hainan cultural innovative industry while developing tourism helps to place Li's bamboo dance into the list of current tourism system and provides a broad stage to show its unique 
charm, thus better realizing a win-win cooperation between financial development and regional dance culture.

In this paper, the origin, development, artistic features, cultural connotation and reasons for the disappearance of Li's bamboo dance are analyzed in detail respectively. The results are listed as follows.

First, although there are many origins of Li's bamboo dance, its religious origin is highly credible. Second, the artistic characteristics of bamboo dance are rich and diverse. The integration of foreign dance action elements makes the native dance of our nation mutate and weaken day by day. In the protection and inheritance, we should first keep the dance form simple. The simple dance form has the connotation and style of history and culture which should be preserved. Secondly, we should enrich the connotation, not only in the form of dance movements, but also in the cultural connotation. Thirdly, the dance form should be unique, not only focusing on national characteristics, but also paying attention to regional characteristics. Emphasizing the regional characteristics of bamboo dance is beneficial to maintain the form and regional characteristics of $\mathrm{Li}$ dance culture and make it more valuable for protection. Third, with the development of the times, the nature, content and form of expression of $\mathrm{Li}$ bamboo dance have changed greatly. Originally performed in the funeral environment, dance has developed into entertainment and fitness dance, which is deeply loved by people. Among many ethnic groups in China, there are Korean "Nongle dance" and Tujia "Maogusi dance" in Western Hunan. In the protection and inheritance, we should pay attention to expanding the influence of regional intangible cultural heritage dance in people's life, broadening the communication field and improving the communication frequency. Fourth, The simplification and Sinicization of Li's funeral rites in Hainan have changed the function and social value of Li's bamboo dance; In the process of protection and inheritance, we should establish local protection institutions, improve the public service system, and set up transmission centers, so that the intangible cultural heritage culture can take root among the people, form a virtuous circle, become a complete system with hematopoietic function, and truly realize the living inheritance. Fifth, the lack of successors, the rapid development of economy and culture, the insufficient government support, the weak awareness of people's protection of their national regional culture, and the acceleration of high-tech and urbanization have become the factors affecting the protection and inheritance of $\mathrm{Li}$ bamboo dance. The author believes that it is very important to protect the inheritors in the protection of intangible cultural heritage dance culture. The inheritance of dance culture is mainly through "body teaching". If there is no inheritor to inherit and spread, the dance culture will face loss. The rapid development of science, technology and economy urges us to keep pace with the times, make full use of the world's advanced scientific media digital technology to realize the simulation of time and space, and let people fully understand the charm of Hainan Li bamboo dance. The limitation of this study is that at present, the research on regional dance in China has reached a certain breadth and depth. Hainan Li bamboo dance is only a branch of many intangible cultural heritage dances. There are countless similar regional intangible cultural heritage dances. Although they are representative, they cannot represent all, so they have certain limitations.

In the live transmission of Li's bamboo dance, lack of careful protection and excessive innovation are two big challenges. To enhance the awareness of its protection, the author believes that education plays a key role. It needs local government to implement relevant incentives, speed up the cultivation of dance talents, and develop the cultural tourism along with the combination of intangible cultural heritage with digital media. In terms of excessive innovation, it results from the adoption of continuous new countermeasures put forward by others. But their feasibility still needs to be testified one by one, and we will continue to pay attention to the follow-up study.

It is a long journey to study live transmission of China's regional dance. In-depth research on Li's bamboo dance can provide a clear path for its development and protection of China's regional dance. Although the development and utilization of ethnic minority culture in Hainan Province has achieved some results in singing and dancing, instrumental music, brocade, customs, and habits, etc., the 
protective development of ethnic culture in Hainan has not been well promoted, and the "brand" value of ethnic culture has not been fully embodied. The excellent regional culture in the construction of international tourism island in the national culture tourism brand status and competitiveness has not been really established. Hainan Li's bamboo dance is only one kind of numerous regional dances. Although they have something in common, one cannot display the unique features of others due to regional difference. The same is true for the analysis, exploration, protection, and inheritance of China's regional dance. It is hoped that follow-up research will provide valuable reference for the live transmission of China's regional dance.

\section{References}

[1] http://www.ihchina.cn/China intangible cultural heritage, June 26 (2019)

[2] Q. Zhao, X. Q. Fang, Chinese Localization of Musicals Co-developed by Korea and China: A Case Study on the Musicals "Bachelor's Vegetable Store", "In the Mood for Sorrow", and "Rimbaud", Asia-pacific Journal of Convergent Research Interchange, (2020), Vol.6, No.9, pp.151-167.

[3] J. W. Xu, X. Q. Fang, Protection and Inheritance of Local Dramas in China: A Case Study of Liuqin Troupe in Pizhou City, The Eastern Art, (2021), No.52, pp.209-247.

[4] X. Q. Fang, E. J. Ryu, A Historical Study of the Zhu, a Traditional Chinese String Instrument, Culture and Convergence, (2020), Vol.42, No.10, pp.415-444, DOI : 10.33645/cnc.2020.10.42.10.415

[5] K. Wang, On the inheritance and development of Hainan Li Folk Dance, Chinese artist, (2020), No.4, pp.132-135, https://kns.cnki.net/kcms/detail/detail.aspx?dbcode=CJFD\&dbname=CJFDLASN2020\&filename=ZWNJ202004043\&un iplatform=NZKPT\&v=1_8BWIcn_teCONgYUXp_uGdrOVsMopEYtJvxLRjNE9S7fvKiYhassC41nphEKM7

[6] R. Q. Sun, Cultural characteristics and style characteristics of Hainan Li dance, Popular literature and art, (2019), No.17, pp.162-163.

[7] Y. Jiang, Cultural and artistic value and inheritance of Li people dance, Journal of Jilin Radio and Television University, (2017), No.12, pp.34-35.

[8] G. Ya, The artistic evolution path of Li people's ancestor worship songs and dances Take Sanya ancestor worship song and dance as an example, Journal of Hainan Tropical Ocean University, (2018), Vol.25, No.4, pp.44-48, DOI : 10.13307/j.issn.2096-3122.2018.04.07

[9] J. H. An, On the form and social function of Li nationality's bamboo dance, Artist, (2019), No.5, pp.62-64, https://kns.cnki.net/kcms/detail/detail.aspx?dbcode=CJFD\&dbname=CJFDLASN2019\&filename=YSJA201905136\&uni platform=NZKPT\&v=EFfCS-cYyk22PIT3cKA3OHe02EOYIFc7YxA1u8FDRfXWYLDzGiy1tAtZLkke4GB-

[10] B. L. Duan, Intangible Cultural Heritage, China Social Literature Press, (2018)

[11] Integrated Editorial Department of Chinese Folk Dance, Chinese Folk Dance Collection (Hainan Volume), Published by China Beijing ISBN Center, (2019), https://mbook.kongfz.com/270335/2097630371/

[12] S. D. Hao, W. B. Huang, Luobidong site in Sanya, Southern publishing house, (2018)

[13] X. Q. Fang, A Study on the Compositional Techniques of Debussy's "Rhapsody No.1 for Clarinet and Piano", Asia-pacific Journal of Convergent Research Interchange, (2021), Vol.7, No.4, pp.35-44.

[14] X. J. Wang, G. Xu, Y. Zhou, Chronicles: Li Fangyi, Li Qing, Li nationality collection local chronicles Department: Volume 3, Hainan Publishing House, (2020)

[15] M. X. Ai, Strategies for the Protection and Inheritance of Ethnic Folk Dancing from the Perspective of Intangible Cultural Heritage, Journal of Pu'er University, (2021), Vol.37, No.1, pp.96-98.

[16] X. P. Wang, Li Nationality in China, Ethnic Publishing House, (2019) 
[17] K. J. Barng, A Study on Non-verbal Visualization Elements of Traditional Performing Arts, International Journal of Interactive Storytelling, (2018), Vol.2, No.2, pp.13-18, http://dx.doi.org/10.21742/IJIS.2018.2.2.03

[18] L. Yuan, Research on Interactively Digital Display for Cultural Heritage-Discovering the Hall of Mental Cultivation: A Digital Experience Exhibition, Asia-pacific Journal of Convergent Research Interchange, (2020), Vol.6, No.8, pp.51-67.

[19] M. Yan, Y. X. Fu, Classification of Li Nationality Dance and its representative works, Literary life Literature and Art Theory, (2014), No.8, pp.154,167.

[20] Y. E. Kim, J. S. Nam, S. H. Nam, A Study on the Spatial Allocation of 360 VR Contents: Centered on Korean Traditional Dance Bosangmu, International Journal of Beauty Science and Technology, (2018), Vol.2, No.2, pp.19-24.

[21] J. M. Hyo, Y. I. Sun, QSoSA (Quad-Space of Stage Acting) Model for Systematic Space Analysis of Stage Acting Based on Hermann Schmitz's Concept of Space, Asia-pacific Journal of Convergent Research Interchange, (2020), Vol.6, No.1, pp.1-18.

[22] K. A. Vardhan, Some Studies on Digital Image Segmentation Techniques, Asia-pacific Journal of Convergent Research Interchange, (2019), Vol.5, No.1, pp.77-89.

[23] Z. Y. Chen, R. Zhang, Spread of Hainan Culture in the Background of Free Trade Port, HaiNan Li Biao Cultural Forum, https://www.hainan.gov.cn/hainan/ztfaxw/202007/34dd13d5078f45b5ac49ac75b8c000b8.shtml 